\title{
Micro-particle filter made in SU-8 for biomedical applications
}

Noeth, Nadine-Nicole; Keller, Stephan Urs; Fetz, Stefanie; Geschke, Oliver; Boisen, Anja

Published in:

International Solid-State Sensors, Actuators and Microsystems Conference, 2009. TRANSDUCERS 2009.

Link to article, DOI:

10.1109/SENSOR.2009.5285663

Publication date:

2009

Document Version

Publisher's PDF, also known as Version of record

Link back to DTU Orbit

Citation (APA):

Noeth, N-N., Keller, S. U., Fetz, S., Geschke, O., \& Boisen, A. (2009). Micro-particle filter made in SU-8 for biomedical applications. In International Solid-State Sensors, Actuators and Microsystems Conference, 2009. TRANSDUCERS 2009. (pp. 2034-2037). IEEE. https://doi.org/10.1109/SENSOR.2009.5285663

\section{General rights}

Copyright and moral rights for the publications made accessible in the public portal are retained by the authors and/or other copyright owners and it is a condition of accessing publications that users recognise and abide by the legal requirements associated with these rights.

- Users may download and print one copy of any publication from the public portal for the purpose of private study or research.

- You may not further distribute the material or use it for any profit-making activity or commercial gain

- You may freely distribute the URL identifying the publication in the public portal 


\title{
MICRO-PARTICLE FILTER MADE IN SU-8 FOR BIOMEDICAL APPLICATIONS
}

\author{
N. Noeth*, S. Keller, S. Fetz, O. Geschke, A. Boisen \\ DTU Nanotech, Technical University of Denmark, Kongens Lyngby, Denmark
}

\begin{abstract}
We have integrated a micro-particle filter in a polymer cantilever to filter micro-particles from a fluid while simultaneously measuring the amount of filtered particles. In a $3,8 \mu \mathrm{m}$ thick SU-8 cantilever a filter was integrated with pore sizes between 3 and $30 \mu \mathrm{m}$. The chip was inserted in a microfluidic system and water with differently sized polystyrene beads was pumped through the filter. Particles which are larger than the pore sizes, cannot pass the filter and will increase the flow resistance of the cantilever. With more and more captured particles the cantilever starts to deflect, which can be detected by an optical read-out system.
\end{abstract}

\section{KEYWORDS}

SU-8, filter, microfluidic system, cantilever

\section{INTRODUCTION}

In the field of Biology and Medicine it is often difficult and expensive to retrieve large sample sizes of different liquids like blood, pathogen or cell suspensions and protein or antibody solutions.

Current practice for example requires 10 to $30 \mathrm{ml}$ of blood has to be drawn from a person to carry out a standard blood test. This can be quite inconvenient for a patient, when it has to be done frequently.

With the support of Microfluidic systems sample sizes below $1 \mathrm{ml}$ can be controlled and manipulated.

In microfluidic systems filters are used instead of centrifuges to separate inhomogeneous solutions, like blood. There are various microfluidic filters, which for example separate the plasma from a whole blood sample [1] or filter the leukocytes from the erythrocytes and/or blood platelets [2]. With these filters a second separate test step is necessary to measure the amount of filtered material, which causes not only more costs and time but also increases the risk of sample degradation.

Cantilevers are widely used for biomedical applications due to the rapid, label-free and in-situ detection of specific bio/chemical analytes, especially in aqueous environments [3], [4].

Here these two technologies are combined and cantilevers with an integrated filter function are fabricated. This enables the separation of micro-particles from a liquid while simultaneously measuring the amount of filtered particles using an optical read-out system. SU-8, an epoxybased negative photoresist, is used as the material for the micro-particle filters. Due to the low Young's modulus of SU-8 the flexibility of the cantilevers increases and with that a higher sensitivity of the device can be achieved. The fabrication of a test system and first preliminary measurements of the filtering function are demonstrated.

\section{PRINCIPLE}

Figure 1 shows the general working principle of the micro-particle filter. The cantilever with an integrated filter function is inserted in a microfluidic channel in which a solution with particles flows perpendicular to the polymer beam. Due to the integration of a grid in the cantilever, small particles can pass the filter, where larger ones clog the filter pores. When more and more particles are captured the flow resistance of the system increases and the cantilever starts to bend. The bending of the cantilever depends on the flow velocity of the solution, the amount of caught particles, the dimensions of the filter and the Young's modulus of the cantilever.

With the help of an aluminum pad at the end of the beam the bending of the cantilever can be read out optically. A laser is focused on the aluminum pad and reflected onto a photo diode, which detects the exact position of the cantilever.

With an array of filters with decreasing pore sizes, the same size separation as in a centrifuge can be achieved, and the amount of filtered material can be measured at the same time.

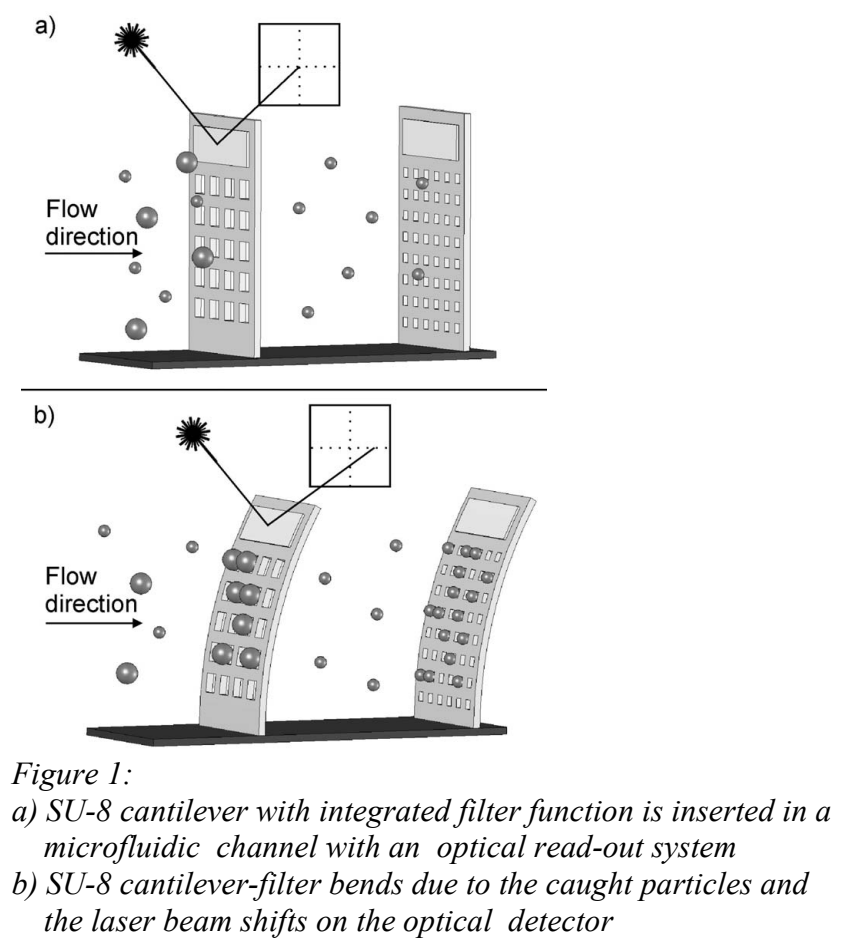




\section{FABRICATION}

The test setup consists of three main parts: A SU-8 chip, a microfluidic setup and a optical read-out system.

The SU-8 chip consists of a micro-particle filter and a channel inlet of the system. Figure 2 shows the fabrication sequence and Figure 3 a microscope picture of the filter on the cantilever.

A hydrophobic fluorocarbon film, as a non-adhesive release layer, was deposited on a Si-substrate, see Figure 2.b) [5]. The cantilevers were realized by spin-coating SU-8 2005 onto the substrate with a resulting thickness of 3,8 $\mu \mathrm{m}$ (Karl Suss RC8-THP spin coater), see Figure 2.c). After solvent evaporation at room temperature for $3 \mathrm{~h}$, the SU-8 layer was structured by a standard UV exposure (SUSS Mask Aligner MA6/BA6) and baked for $1 \mathrm{~h}$ at $50{ }^{\circ} \mathrm{C}$ [6]. The development was carried out in PGMEA for $2 \times 2 \mathrm{~min}$. To improve the stability of the polymer a short flood-exposure (SUSS Mask Aligner MA6/BA6) and a $13 \mathrm{~h}$ hardbake at $120^{\circ} \mathrm{C}$ was executed to ensure fully cross-linked SU-8 structures, see Figure 2.d).

The exposure parameters were optimized and a gap of only $5 \mu \mathrm{m}$ between the microfluidic channel and the cantilever $(400 \times 400 \mu \mathrm{m})$ was achieved. The filter consists of grid and honeycomb structures with hole diameters varying from 3 to $30 \mu \mathrm{m}$ and hole to hole distances from 5 to $10 \mu \mathrm{m}$.

A $60 \mathrm{~nm}$ thick aluminum layer was e-beam evaporated and patterned (Alcatel SCM 600 E-beam metal deposition system) during a standard negative lift-off process, see Figure 2.e) and f).

After that the microfluidic channel was formed by spin coating SU-8 2075 onto the thin layer of SU-8 with a resulting thickness of $300 \mu \mathrm{m}$, see Figure 2.g). After a softbake for 12 hours at $50{ }^{\circ} \mathrm{C}$ and a UV exposure a postexposure bake for 12 hours at $50{ }^{\circ} \mathrm{C}$ was executed. This was followed by the development for $2 \times 15 \mathrm{~min}$ in PGMEA, see Figure 2.h) [6].

Since the cantilevers with filter function were extremely fragile, they broke during the dry release step with tweezers. Therefore, a dry isotropic silicon etch step (STS MESC Multiplex ICP) was added to the standard fabrication process of SU-8 cantilevers. It undercut the $3 \mathrm{D}$ structured cantilevers, so that they were free standing before the release with tweezers, see Figure 2.i) and j). During the optimization of the etch step four different parameters were varied: Flow rate of $\mathrm{SF}_{6}$, flow rate of $\mathrm{O}_{2}$, coil power and chuck temperature. Based on the optimization results the best parameter combination for the isotropic etch step is $\mathrm{SF}_{6}=300 \mathrm{sccm}$, coil power = $1500 \mathrm{~W}, \mathrm{~T}=10^{\circ} \mathrm{C}, \mathrm{O}_{2}=0 \mathrm{sccm}$ at an etch time of $5 \mathrm{~min}$. With the additional process step the release yield could be increased from $46,3 \%$ to $80,3 \%$.

Finally, a release bake for $2 \mathrm{~h}$ at $120{ }^{\circ} \mathrm{C}$ was added to the standard fabrication process to even further improve the release yield.

The released SU-8 chips were sealed via single chip bonding by gluing a Silicon tape (Arcare 91005) on the top of the SU-8 channel.

a)

Si-substrate

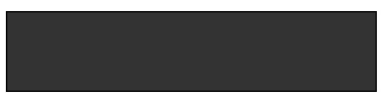

c)

3,8 $\mu \mathrm{m}$ thick SU-8

spin coating

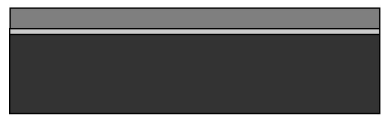

e)

spin coating and patterning

of $A Z$ resist and

Aluminum deposition

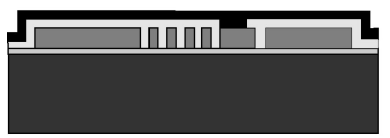

g)

$300 \mu \mathrm{m}$ thick SU-8

spin coating

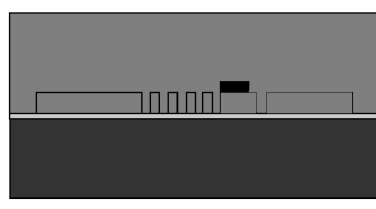

i)

isotropic under-etch and

release bake

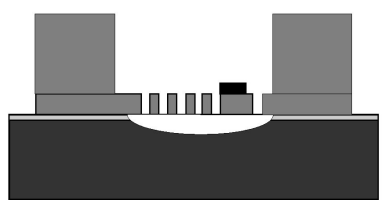

Figure 2:

SU-8 fabrication process of the cantilever-filter chip

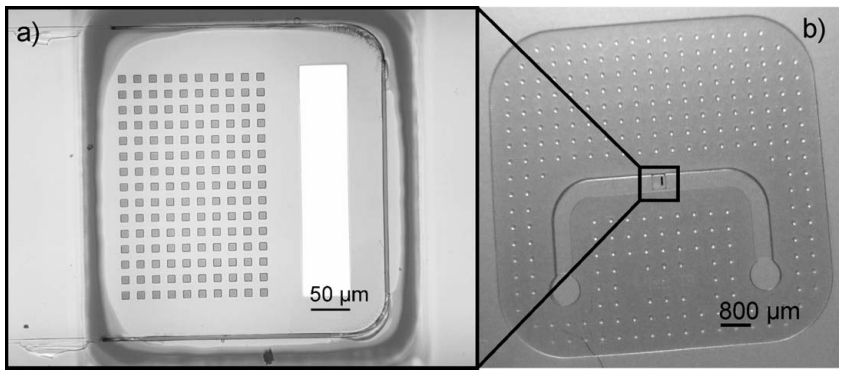

Figure 3:

a) Top view of a cantilever with integrated filter function (pore size $9 \mu \mathrm{m})$ and an aluminum pad at the end of the beam

b)Top view of the SU-8 chip with a microfluidic channel and a cantilever in the middle b)

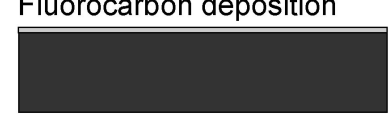

d) with filter function

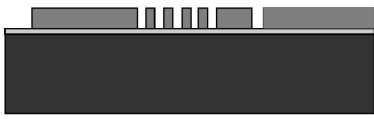

f)

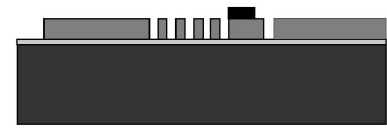

h)

Patterning of the body-chip

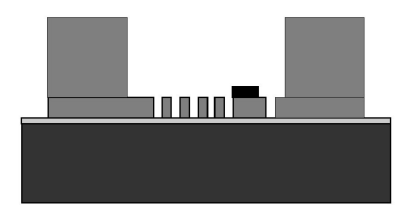

j)

release with tweezers

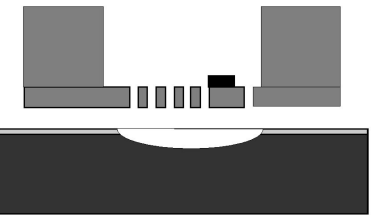


The microfluidic setup consists of four parts: A PMMA base-plate, a PDMS sealing, which includes a channel outlet, a glass plate and a PMMA top-plate. The $5 \mathrm{~mm}$ thick PMMA base-plate was structured with the micro-milling machine Mini-Mill/3PRO. It includes four inlets for the tubings and four screws to tighten and seal the system. The $1,5 \mathrm{~mm}$ thick PMMA top-plate is structured by a $\mathrm{CO}_{2}$ laser (48-5S Duo Lase carbon dioxide laser) and annealed afterwards for half an hour at $85^{\circ} \mathrm{C}$ to decrease the induced stress. It has a window at the position of the SU-8 chip to reduce the interference with the laser, and four holes for the screws to tighten the system. The PDMS sealing was first spin-coated onto a $\mathrm{Si}$ wafer with a thickness of $300 \mu \mathrm{m}$ and after a short annealing of $10 \mathrm{~min}$ at $85{ }^{\circ} \mathrm{C}$ the outlet channel was patterned by the $\mathrm{CO}_{2}$ laser [7].

Figure 4 shows how the microfluidic system is assembled and how the fluid flows through the system. The glass plate on top of the SU-8 chip is necessary to be able to apply a higher pressure on the system to avoid leaking without breaking the SU-8 chip or the PMMA topplate.

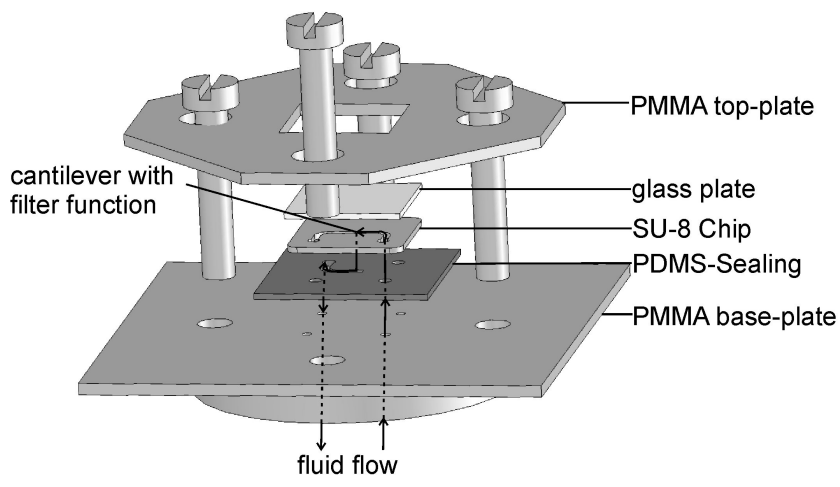

Figure 4:

Microfluidic setup with SU-8 chip and direction of fluid flow through the system

The whole microfluidic setup with the SU-8 chip was inserted in a laser-setup prototype from Danish Micro Engineering A/S (DME). There, a standard diode laser was focused on the aluminum pad at the tip of the cantilever and the reflection was detected by a photodiode. The location of the laser reflection on the detector in $\mathrm{x}$ - and $\mathrm{y}$ direction was measured via voltmeters. The read-out was done via an acquisition software which was programmed in Labview (National Instruments). For this setup a voltage difference of $1 \mathrm{~V}$ corresponds to approximately $5 \mu \mathrm{m}$ deflection of the cantilever.

\section{RESULTS}

Before every measurement all channels were filled and flushed with deoxygenated water to reduce the air bubbles in the system. Then the laser and the photodiode were aligned to the chip, so the position of the laser reflection was in the middle of the detector. For all experiments the same kind of filter (grid: hole size $9 \mu \mathrm{m}$ ) was used.

Figure 5 shows the influence of the flow velocity on the deflection of the cantilever after drift-correction. Three different velocities $(50 \mu \mathrm{l} / \mathrm{min}, 100 \mu \mathrm{l} / \mathrm{min}$ and $150 \mu \mathrm{l} / \mathrm{min})$ were tested. To change the flow velocity the microfluidic pump had to be turned off, which explains the peaks between the different velocity steps. It can be seen, that an increasing flow velocity causes an increase of the deflection of the SU-8 cantilever.

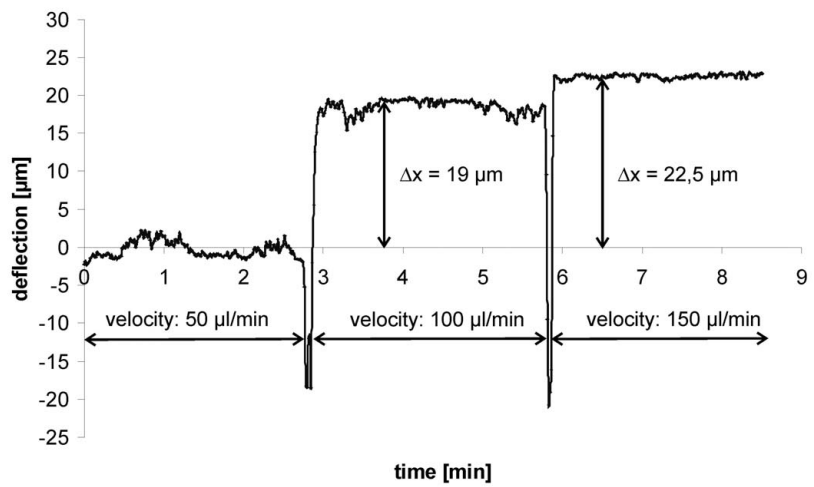

Figure 5:

Deflection of a cantilever-filter at three different flow velocities after drift-correction

Further experiments were executed at the minimal flow velocity of $50 \mu \mathrm{l} / \mathrm{min}$. To measure the influence of micro-particles on the cantilever-filter the system was flushed with degassed water to record the baseline and after $8 \mathrm{~min}$ polystyrene beads (Polyscience) with diameters of 2 and $10 \mu \mathrm{m}$ diluted in MilliQ water were injected. Figure 6 shows the deflection of the cantilever and Figure 7 shows the top view of the system through a microscope during the experiment. After the injection of the particles it can be seen, that the $2 \mu \mathrm{m}$ particles pass easily through the filter and the $10 \mu \mathrm{m}$ particles start to accumulate on the grid. This not only causes the cantilever to bend but also accounts for a higher noise of the system as more and more particles cover the aluminum pad. Approximately 5 min after the injection sufficient particles are captured by the cantilever-filter to bend it more than $10 \mu \mathrm{m}$. With that, all new arriving particles just pass through the opening between the cantilever and the microfluidic channel wall, and the cantilever deflection remains constant. 


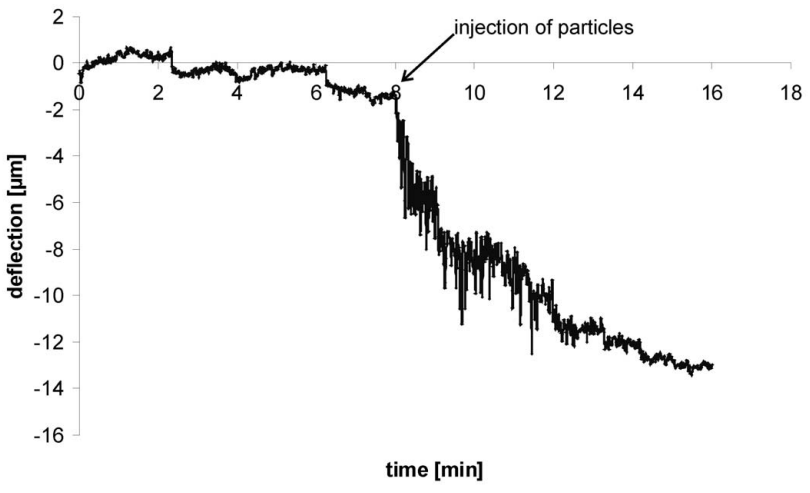

Figure 6:

Deflection of cantilever-filter before and after injection of micro-particles with diameter of 2 and $10 \mu \mathrm{m}$
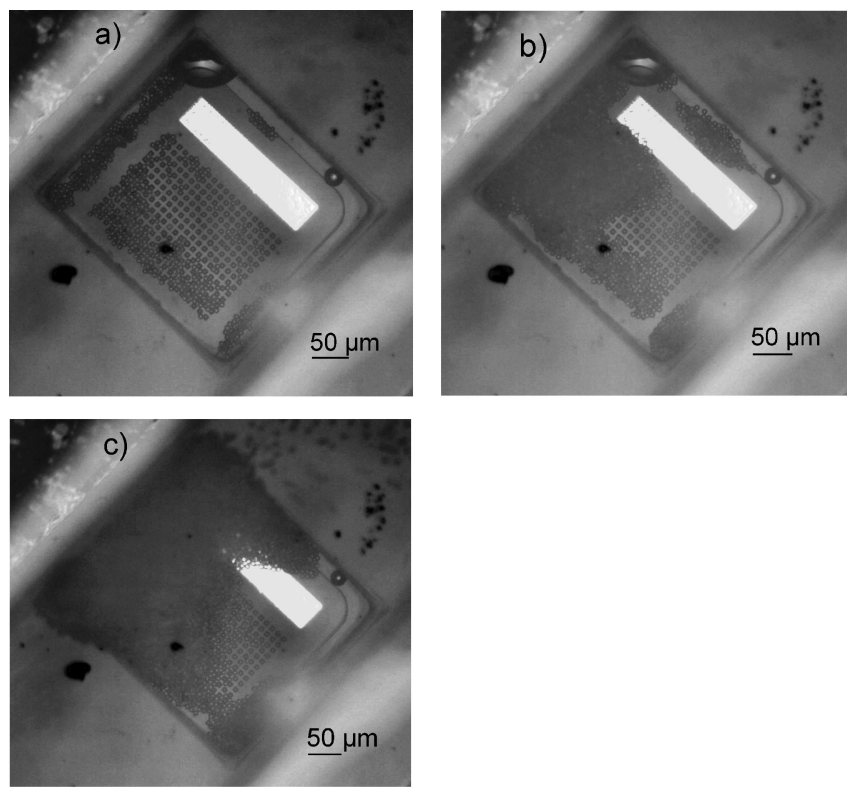

Figure 7:

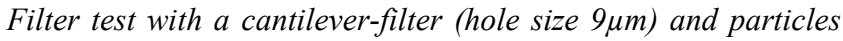
of the size 2 and $10 \mu \mathrm{m}$

a) $2 \mathrm{~min}$

b) $4 \mathrm{~min}$

c) 5 min after the injection of particles

\section{CONCLUSION AND OUTLOOK}

We have shown that it is possible to filter microparticles from a solution and to measure the deflection of a cantilever, which corresponds to the amount of filtered particles simultaneously.

A $3,8 \mu \mathrm{m}$ thick cantilever with an integrated filter function and the channel inlet was fabricated in SU-8. After the optimization of the SU-8 fabrication process pore sizes of $3 \mu \mathrm{m}$ could be patterned and with the additional isotropic etch step a high release yield of these fragile structures could be achieved. The microscope inspection showed, that the cantilever-filters are straight enough to close the microfluidic channel for large particles.

The microfluidic setup with a channel outlet was fabricated in PMMA and PDMS. The injection of particles and their influence on the bending of the cantilever in the system was measured via an optical leverage read-out system. It was shown, that with an increasing amount of captured particles the deflection of the cantilever-filter increases and that the water flow at a small enough velocity has almost no influence on the filter deflection, since the water can just pass through.

Future work will include an optimization of the SU-8 chip, the microfluidic setup and the laser read-out system to reduce the noise and to increase the signal. Further tests with biological materials, like blood or urine are planned to proof the applicability in the medical field. A key goal is to quantify the amount of captured particles from the deflection of the cantilever, allowing us to stop the fluid flow before particles pass through the gap between the deflected cantilever and the microfluidic channel wall.

\section{REFERENCES}

[1] J.P. Brody, T.D. Osborn, F.K. Forster, P. Yager, "A planar microfabricated fluid filter", Sensors and Actuators, A 54, pp. 704-708, 1996

[2] C.J.M. van Rijn, M.C. Elwenspoek, "Micro filtration Membrane Sieve with Silicon Micro Machining for Industrial and Biomedical Applications", Proceedings IEEE Micro Electro Mechanical Systems, pp. 83-87, 1995

[3] M. Nordström, S. Keller, M. Lillemose, A. Johansson, S. Dohn, D. Haefliger, G. Blagoi, M. Havsteen Jakobsen, A. Boisen, "SU-8 Cantilevers for Bio/chemical Sensing; Fabrication, Characterisation and Development of Novel Read-out Methods", Sensors, vol. 8, pp. 1595-1612, 2008

[4] M. Calleja, M. Nordström, M. Álvarez, J. Tamayo, L.M. Lechuga, A. Boisen, "Highly sensitive polymerbased cantilever-sensors for DNA detection", Ultramicroscopy, vol. 105, pp. 215-222, 2005

[5] S. Keller, D. Haefliger, A. Boisen, "Optimized plasma-deposited fluorocarbon coating for dry release and passivation of thin SU-8 cantilevers", J. Vac. Sci. Technol. B, vol. 25 (6), pp. 1903-1908

[6] S. Keller, G. Blagoi, M. Lillemose, D. Haefliger, A. Boisen, "Processing of thin SU-8 films", $J$. Micromech. Microeng., vol. 18, pp. 125020, 2008

[7] H. Klang, J.P. Kutter, O. Geschke, " $\mathrm{CO}_{2}$-laser micromachining and back-end processing for rapid production of PMMA-based microfluidic systems", Lab on a chip, vol. 2(4), pp. 242-246, 2002

\section{CONTACT}

*N. Noeth, tel.: +45-4525-5759; nadine.noeth@nanotech.dtu.dk 